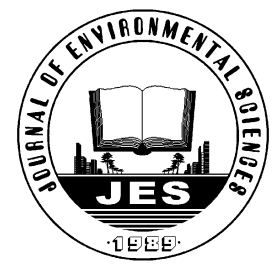

\title{
pH modeling for maximum dissolved organic matter removal by enhanced coagulation
}

\author{
Jiankun Xie ${ }^{1}$, Dongsheng Wang ${ }^{1, *}$, John van Leeuwen ${ }^{1,2}$, Yanmei Zhao ${ }^{1}$, \\ Linan Xing ${ }^{1}$, Christopher W. K. Chow ${ }^{1,3}$ \\ 1. State Key Laboratory of Environmental Aquatic Chemistry, Research Center for Eco-Environmental Sciences, \\ Chinese Academy of Sciences, Beijing 100085, China. E-mail: jkxie_st@rcees.ac.cn \\ 2. SA Water Centre for Water Management and Reuse, NBE, University of South Australia, Australia \\ 3. Australian Water Quality Centre, SA Water, 250 Victoria Square, Adelaide, SA 5000, Australia
}

Received 11 February 2011; revised 06 May 2011; accepted 10 May 2011

\begin{abstract}
Correlations between raw water characteristics and $\mathrm{pH}$ after enhanced coagulation to maximize dissolved organic matter (DOM) removal using four typical coagulants $\left(\mathrm{FeCl}_{3}, \mathrm{Al}_{2}\left(\mathrm{SO}_{4}\right)_{3}\right.$, polyaluminum chloride $(\mathrm{PACl})$ and high performance polyaluminum chloride (HPAC)) without $\mathrm{pH}$ control were investigated. These correlations were analyzed on the basis of the raw water quality and the chemical and physical fractionations of DOM of thirteen Chinese source waters over three seasons. It was found that the final $\mathrm{pH}$ after enhanced coagulation for each of the four coagulants was influenced by the content of removable DOM (i.e. hydrophobic and higher apparent molecular weight (AMW) DOM), the alkalinity and the initial $\mathrm{pH}$ of raw water. A set of feed-forward semi-empirical models relating the final $\mathrm{pH}$ after enhanced coagulation for each of the four coagulants with the raw water characteristics were developed and optimized based on correlation analysis. The established models were preliminarily validated for prediction purposes, and it was found that the deviation between the predicted data and actual data was low. This result demonstrated the potential for the application of these models in practical operation of drinking water treatment plants.
\end{abstract}

Key words: enhanced coagulation; modeling; DOM fractionation; $\mathrm{pH}$ control

DOI: $10.1016 /$ S1001-0742(11)60717-1

\section{Introduction}

Natural dissolved organic matter (DOM) present in source waters for drinking water supplies is a complex matrix of heterogeneous organic material. It can be sourced from decaying terrestrial vegetation and aquatic organisms. The presence of DOM in drinking water supplies may cause significant problems, such as, reacting with chlorine disinfectant to reduce its concentration, reacting with chlorine to form disinfection byproducts such as THMs, HAA and other organohalogens, supporting bacterial re-growth in the distribution system and contributing to color, taste and odor in drinking water. Therefore, maximizing the removal of DOM in water has become a significant issue for the drinking water industry. Enhanced coagulation is the application of higher coagulant doses to achieve regulatory criteria for set removals of total organic carbon (TOC) based on raw water quality or to minimize residual DOM after coagulation in drinking water supplies. The US Environmental Protection Agency, under the Safe Drinking Water Act and the Disinfectants/Disinfection Byproducts Rule (D/DBPR), has enhanced coagulation as a best avail-

\footnotetext{
* Corresponding author. E-mail: wgds@ rcees.ac.cn
}

able technology for DOM removal (Chow et al., 2008; Edwards, 1997; Kastl et al., 2004; van Leeuwen et al., 2003).

Removal of DOM by enhanced coagulation is greatly influenced by the chemical and physical characteristics of DOM in raw water. Resin adsorption (RA) is an effective method for chemical fractionation and has been widely employed for the characterization of DOM based on its chemical properties in past years (Kitis et al., 2002; Leenheer, 1981; Leenheer and Croue, 2003; Martin-Mousset, 1997; Wei et al., 2008). XAD-8 (or DAX-8) and XAD-4 resins have been used to determine the humic/nonhumic distributions of DOM. In recent years, high performance size exclusion chromatography (HPSEC) with DOC and or UV-Visible detection has become a popular technique for characterization of DOM based on its physical properties (molecular weight distribution) and for evaluation of water treatment processes (Allpike et al., 2005; Bolto et al., 2001; Chin et al., 1994; Chow et al., 1999; Gjessing et al., 1998; Her et al., 2008; van Leeuwen et al., 2002; Vuorio et al., 1998). However, the apparent molecular weight (AMW) distribution profile of DOM with overlapped peaks can only provide qualitative information by comparing the profiles of different raw waters or waters before and after 
certain treatment processes. To obtain more quantitative information, Chow et al. (2008) developed a peak fitting technique to resolve the overlapped peaks into several individual peaks which representing the removable or nonremovable DOM. These DOM characterization techniques provided the most useful information for the drinking water treatment.

Quantitative descriptions of the removals of DOM and its constituents by enhanced coagulation are of significant importance in the coagulation research field. Recently, considerable number of publications aimed at developing models of DOM removal by enhanced coagulation (Edwards, 1997; Urfer et al., 1999; Baxter et al., 1999; Stanley et al., 2000; van Leeuwen et al., 2003, 2005; Kastl et al., 2004; Chow et al., 2008). Several empirical and semi-empirical models have been developed based on the regression analysis and artificial neural network (ANN), while some others were based on consideration of the character and quantity of DOM, such as those utilizing Langmuir adsorption isotherm theory. However, only few models (van Leeuwen et al., 2003, 2005) described the relationship between the raw water characteristics, dosing to achieve enhanced coagulation, and the final $\mathrm{pH}$ reached after enhanced coagulation.

In the previous work, raw waters from thirteen Chinese drinking source waters collected over three seasons had been characterized based on general water quality parameters and chemical fractionation (RA method) in conjunction with physical fractionation (HPSEC combined with peak fitting technique). Furthermore, several models that describe the DOM treatability by enhanced coagulation and the dosage required for enhanced coagulation for four coagulants had been developed. In this article, based on the previous work, a set of feed-forward semi-empirical models that relate the raw water characteristics with the final $\mathrm{pH}$ after enhanced coagulation ( $\mathrm{EC} \mathrm{pH}$, i.e. the $\mathrm{pH}$ in the enhanced coagulation condition) for maximum DOM removal without $\mathrm{pH}$ control for four coagulants were developed and optimized.

\section{Materials and methods}

\subsection{Coagulants}

Four coagulants were selected, including ferric chloride $\left(\mathrm{FeCl}_{3} \cdot 6 \mathrm{H}_{2} \mathrm{O}\right.$, analytical grade), aluminum sulfate $\left(\mathrm{Al}_{2}\left(\mathrm{SO}_{4}\right)_{3} \cdot 18 \mathrm{H}_{2} \mathrm{O}\right.$, analytical grade), polyaluminum chloride $(\mathrm{PACl}, \mathrm{OH} / \mathrm{Al}=2.4$, prepared in the laboratory) and high performance polyaluminum chloride (HPAC, an innovative composite coagulant, produced by a local factory using the technique developed in this laboratory).

\subsection{Water samples}

Twenty nine water samples were obtained from thirteen typical locations throughout eastern China, including Harbin Songhua River, Harbin Mopanshan Reservoir, Beijing South to North Transport Project Water Aque- duct, Tianjin Luan River, Dongying Yellow River, Yantai Menlou Reservoir, Zhengzhou Yellow River, Nantong Changjiang River, Shanghai Huangpujiang River, Xiaoshan Qiantangjiang River, Yuyao Siminghu Reservoir, Guangzhou Xihangdao River and Guangzhou Beijiang River from north to south. These waters are all source waters for local drinking water treatment plants and represent the variation in water quality in China. The general water quality parameters of raw water samples have been characterized in the previous work (Xie, 2011).

\subsection{Jar tests}

Jar tests were performed using $500 \mathrm{~mL}$ raw water samples and a programmable jar testing apparatus with the following standard procedure: $30 \mathrm{sec}$ of rapid stirring at $250 \mathrm{r} / \mathrm{min}$ followed by coagulant addition, 2 min of rapid stirring at $250 \mathrm{r} / \mathrm{min}, 15 \mathrm{~min}$ of slow mixing at $40 \mathrm{r} / \mathrm{min}$ and $30 \mathrm{~min}$ of settling. After settling was completed, water samples were collected at $1 \mathrm{~cm}$ below water surface, and were measured for turbidity and $\mathrm{pH}$. Samples were then filtered through $0.45 \mu \mathrm{m}$ cellulose acetate membranes for DOC, $\mathrm{UV}_{254}$ and residual metal analyses, chemical fractionation and physical fractionation.

To simulate the practical operation conditions at water treatment plants in China, the coagulation processes were performed without $\mathrm{pH}$ control, and the jar tests in autumn and spring were performed at the water temperature around $25^{\circ} \mathrm{C}$, whereas those in winter were performed at the water temperature around $8^{\circ} \mathrm{C}$. The enhanced coagulation jar tests were conducted without $\mathrm{pH}$ control for all 29 raw waters using the four coagulants. Dose response curves for DOC, $\mathrm{UV}_{254}, \mathrm{pH}$ and turbidity were obtained.

\subsection{Analytical methods}

Turbidity was measured using a turbidity meter (2100P, Hach, USA). DOC was determined using a total organic carbon analyzer (TOC-VCPH, Shimadzu, Japan). UV 254 was determined using a UV/Vis spectrophotometer (UVVis 8500, Tianmei, China) with a $1 \mathrm{~cm}$ quartz cell. The specific UV absorbance (SUVA) was calculated by $\left(\mathrm{UV}_{254} / \mathrm{DOC}\right) \times 100 . \mathrm{pH}$ was measured using a $\mathrm{pH}$ meter (MP220, Mettler-Toledo, Switzerland). Alkalinity was measured using an automatic titration $\mathrm{pH}$ meter (716 DMS Titrino, Metrohm, Switzerland). The residual metal content was determined using an inductively coupled plasma optical emission spectrometer (OPTIMA 2000, PerkinElmer, USA).

\subsection{Chemical fractionation of DOM}

Chemical fractionation of DOM was performed by resin adsorption method described by Wei et al. (2008). The DOM was fractionated into five chemical fractions: hydrophobic base (HoB), hydrophobic neutral (HoN), hydrophobic acid (HoA), weakly hydrophobic acid (WHoA) and hydrophilic matter (HiM). HoB, HoN, HoA and WHoA could be combined into hydrophobic matter (HoM). HoB, HoN and HoA could be combined into strong hydrophobic matter (SHoM). 


\subsection{Physical fractionation of DOM}

Physical fractionation of DOM was performed by HPSEC and a peak fitting technique described in the previous work (Xie, 2011; Chow et al., 2008). The DOM was fractionated into five physical fractions: Peak 1, Peak 2, Peak 3, Peak 4 and Peak 5. The AMW of the five fractions distributed 250 Da (Peak 1), 450 Da (Peak 2), 1000 Da (Peak 3), 1700 Da (Peak 4) and $2400 \mathrm{Da}$ (Peak 5). For comparative purposes, Peak 4 and Peak 5 could be combined into Peak 4,5. Peak 3, Peak 4 and Peak 5 could be combined into Peak 3,4,5.

\section{Results and discussion}

\subsection{Correlation between the EC $\mathrm{pH}$ and general water quality parameters}

For the purpose of developing models that relate the EC $\mathrm{pH}$ (i.e. the $\mathrm{pH}$ at the enhanced coagulation point) with the raw water characteristics, the enhanced coagulation point for near maximum DOM removal should be consistently determined based on a common procedure. In this study, from the curves of DOC reductions with coagulant dosing, the enhanced coagulation points for the four coagulants for 29 raw water samples were determined when DOC reduction was less than $0.1 \mathrm{mg} / \mathrm{L}$ with dosage increased by $0.1 \mathrm{mmol} / \mathrm{L}$ (as $\mathrm{Al}^{3+}$ or $\mathrm{Fe}^{3+}$ ), i.e., where a gradient (DOC/dosage) of 0.0062, 0.0058, 0.0196 and 0.0196 for $\mathrm{FeCl}_{3}, \mathrm{Al}_{2}\left(\mathrm{SO}_{4}\right)_{3}, \mathrm{PACl}\left(\right.$ as $\left.\mathrm{Al}_{2} \mathrm{O}_{3}\right)$ and $\mathrm{HPAC}\left(\right.$ as $\mathrm{Al}_{2} \mathrm{O}_{3}$ ) was obtained, respectively. At these points derived from the above selected gradients, it was considered that further dosing coagulant would provide only minor DOC removal. At these enhanced coagulation points the residual turbidities were all below 1.5 NTU, and the residual $\mathrm{Al}^{3+}$ and $\mathrm{Fe}^{3+}$ were all below $0.2 \mathrm{mg} / \mathrm{L}$ and $0.3 \mathrm{mg} / \mathrm{L}$, respectively.

To develop models that relate the $\mathrm{EC} \mathrm{pH}$ to raw water characteristics, it is essential to assess the individual relationships between them, and to determine which parameters of raw water most influence the $\mathrm{EC} \mathrm{pH}$. Then models can be established to describe this relationship between $\mathrm{EC} \mathrm{pH}$ and the identified parameters.

The co-efficient of determination values $\left(R^{2}\right)$ of linear fits between the $\mathrm{EC} \mathrm{pH}$ for the four coagulants and the general raw water quality parameters, DOC, $\mathrm{UV}_{254}$, SUVA, alkalinity, $\mathrm{pH}$ and turbidity are shown in Fig. 1. For $\mathrm{FeCl}_{3}$ and $\mathrm{Al}_{2}\left(\mathrm{SO}_{4}\right)_{3}$, the $\mathrm{EC} \mathrm{pH}$ showed moderate negative $R^{2}$ values with the DOC and $\mathrm{UV}_{254}$ and moderate positive $R^{2}$ value with the alkalinity of raw water. For $\mathrm{PACl}$, the EC $\mathrm{pH}$ showed high positive $R^{2}$ values with the alkalinity and initial $\mathrm{pH}$ of raw water. For HPAC, the EC $\mathrm{pH}$ showed moderate positive $R^{2}$ values with the alkalinity and initial $\mathrm{pH}$ and moderate negative $R^{2}$ values with the DOC and $\mathrm{UV}_{254}$ of raw water. It indicated that the EC $\mathrm{pH}$ for the four coagulants was influenced by the combination of some or all of the parameters investigated, i.e. DOM content, alkalinity and $\mathrm{pH}$ of raw water.

Generally, the $\mathrm{pH}$ of raw water decreases after dosing due to the hydrolysis of the coagulant. The alkalinity of raw water is an important influencing factor in the enhanced coagulation process without $\mathrm{pH}$ control, as DOC

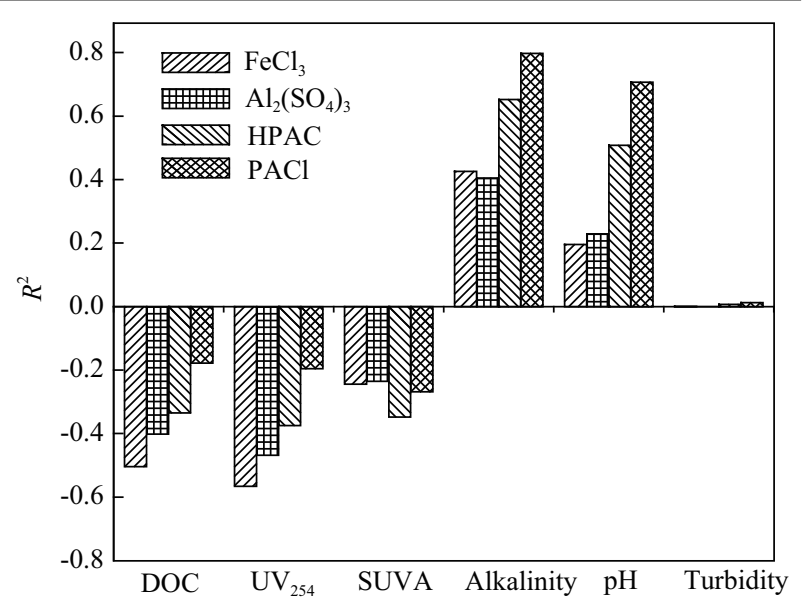

Fig. 1 Co-efficient of determination values $\left(R^{2}\right)$ between the final $\mathrm{pH}$ after enhanced coagulation for the four coagulants and the general raw water quality parameters.

removal efficiency is $\mathrm{pH}$ dependant (Yan et al., 2008). The impact of the raw water alkalinity on the $\mathrm{EC} \mathrm{pH}$ is a function of the level of that alkalinity for each of the four coagulants and the dose required to remove DOM and turbidity that then drives the $\mathrm{pH}$ to where coagulation is optimum for those purposes. In a general sense, specific levels of alkalinity are required to buffer the hydrogen ions produced through hydrolysis and which allows production of metal hydroxide complexes required for desired absorption and charge neutralization processes for coagulation efficiency. The impact of raw water alkalinity on the EC $\mathrm{pH}$ for four coagulants is positive, due to that the higher the raw water alkalinity is, the more $\mathrm{OH}^{-}$is provided to meet the consumption during the coagulant hydrolysis process, the slower the $\mathrm{pH}$ decreases, and the higher the $\mathrm{EC} \mathrm{pH}$ is.

The traditional coagulants $\mathrm{FeCl}_{3}$ and $\mathrm{Al}_{2}\left(\mathrm{SO}_{4}\right)_{3}$ are strongly hydrolyzed after dosing, and the decrease in $\mathrm{pH}$ is significant (Yan et al., 2008). Lower pH is needed to obtain the maximum DOM removal by enhanced coagulation, so the $\mathrm{EC} \mathrm{pH}$ for $\mathrm{FeCl}_{3}$ and $\mathrm{Al}_{2}\left(\mathrm{SO}_{4}\right)_{3}$ is less dependent on the initial $\mathrm{pH}$ of raw water but is very dependent on the alkalinity or buffering capacity of the raw water. This EC pH may be needed to be re-adjusted back to 7 by addition of lime or caustic in the treated water before supply to customers. Whereas, the pre-hydrolyzed coagulants PACl and HPAC are quite stable and are less hydrolyzed after dosing, and the decrease in $\mathrm{pH}$ is low for HPAC and is slight for PACl (Yan et al., 2008). Higher $\mathrm{pH}$ is needed to obtain the maximum DOM removal by enhanced coagulation, so the $\mathrm{EC} \mathrm{pH}$ for $\mathrm{PACl}$ and $\mathrm{HPAC}$ is more dependent on the initial $\mathrm{pH}$ of raw water. The impact of initial $\mathrm{pH}$ of raw water on the $\mathrm{EC} \mathrm{pH}$ for $\mathrm{PACl}$ and HPAC is positive, due to that the higher the initial $\mathrm{pH}$ is, the higher the final $\mathrm{pH}$ is.

The impact of DOM content of raw water on the $\mathrm{EC} \mathrm{pH}$ for $\mathrm{FeCl}_{3}, \mathrm{Al}_{2}\left(\mathrm{SO}_{4}\right)_{3}$ and HPAC is negative, due to that the higher the DOM content of raw water is, the more dosage is needed for enhanced coagulation to be achieved, and the lower the $\mathrm{EC} \mathrm{pH}$ is depressed to. The impact of the DOM content of raw water on the $\mathrm{EC} \mathrm{pH}$ for $\mathrm{PACl}$ is slight, due to that the decrease in $\mathrm{pH}$ is slight after dosing, and the 
increase in dosage needed for enhanced coagulation also impacts the $\mathrm{pH}$ slightly.

\subsection{Development of models based on correlation studies}

To represent the combined influence of alkalinity and DOM content of raw water on the $\mathrm{EC} \mathrm{pH}$ for $\mathrm{FeCl}_{3}$ and $\mathrm{Al}_{2}\left(\mathrm{SO}_{4}\right)_{3}$, the ratio of alkalinity to DOC (Alkalinity/DOC) of raw water was employed as an independent variable for $\mathrm{FeCl}_{3}$ and $\mathrm{Al}_{2}\left(\mathrm{SO}_{4}\right)_{3}$. Similarly to represent the combined impact of alkalinity and $\mathrm{pH}$ of raw water on the $\mathrm{EC} \mathrm{pH}$ for $\mathrm{PACl}$, the product of alkalinity and $\mathrm{pH}$ (Alkalinity $\times \mathrm{pH}$ ) of raw water was employed as an independent variable for PAC. Further, to represent the combined impact of alkalinity, $\mathrm{pH}$ and DOM content of raw water on the $\mathrm{EC} \mathrm{pH}$ for HPAC, the ratio of the product of alkalinity and $\mathrm{pH}$ to DOC (Alkalinity $\times \mathrm{pH} / \mathrm{DOC})$ of raw water was employed as an independent variable for HPAC.

The $\mathrm{EC} \mathrm{pH}$ values of 29 raw water samples for $\mathrm{FeCl}_{3}$, $\mathrm{Al}_{2}\left(\mathrm{SO}_{4}\right)_{3}, \mathrm{PACl}$ and $\mathrm{HPAC}$ were plotted against the values of Alkalinity/DOC, Alkalinity/DOC, Alkalinity $\times \mathrm{pH}$ and Alkalinity $\times \mathrm{pH} / \mathrm{DOC}$ (Fig. 2), respectively. It can be seen that the $\mathrm{EC} \mathrm{pH}$ for all the four coagulants are correlated with their corresponding independent variables of raw water. The following mathematical function was adopted as the basic model to fit the data and represent the
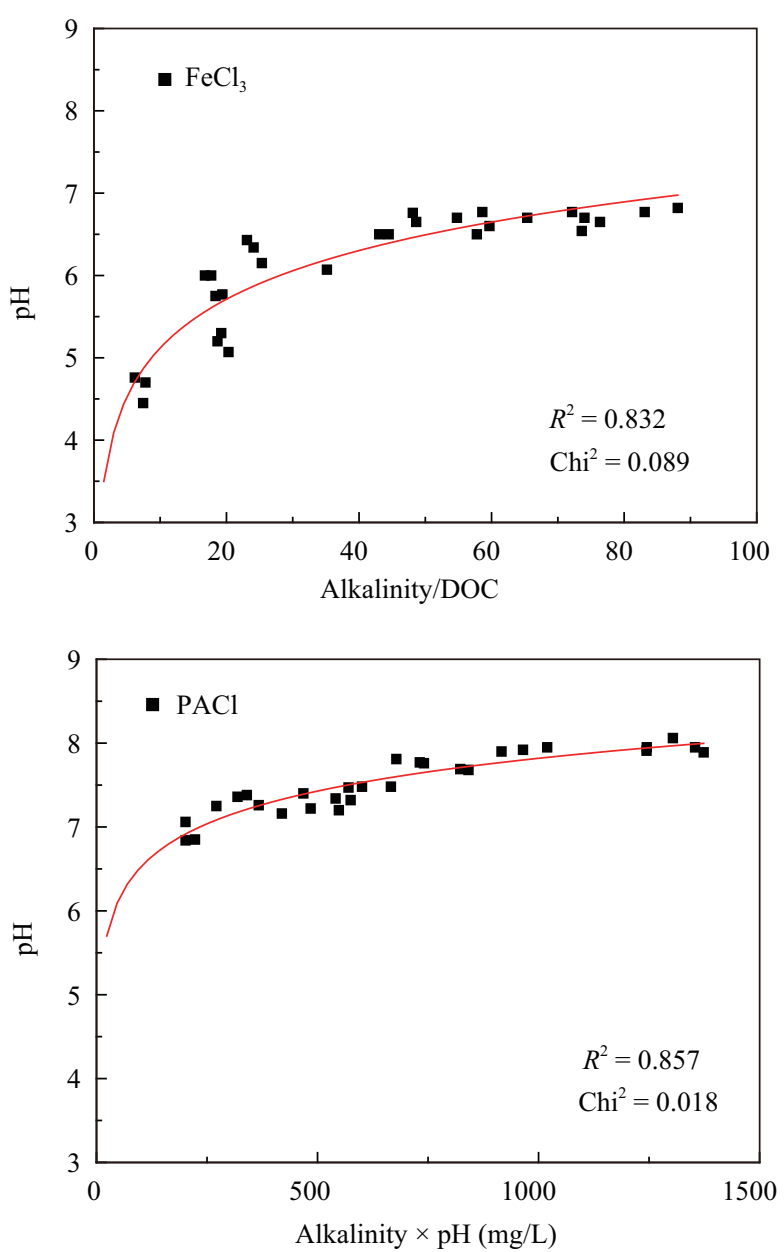

mathematical relationship:

$y=A+B \times \ln (x)$

where, $y$ is the dependent variable, $x$ is the independent variable, and $A$ and $B$ are constants.

Four models that relate the $\mathrm{EC} \mathrm{pH}$ for the four co-

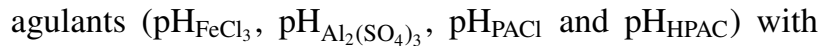
their corresponding independent variables derived from raw water parameters were determined as follows:

$\mathrm{pH}_{\mathrm{FeCl}_{3}}=A_{\mathrm{aa}}+B_{\mathrm{aa}} \times \ln \left(\frac{\text { Alkalinity }}{\text { DOC }}\right)$
$\mathrm{pH}_{\mathrm{Al}_{2}\left(\mathrm{SO}_{4}\right)_{3}}=A_{\mathrm{ab}}+B_{\mathrm{ab}} \times \ln \left(\frac{\text { Alkalinity }}{\mathrm{DOC}}\right)$
$\mathrm{pH}_{\mathrm{PACl}}=A_{\mathrm{ac}}+B_{\mathrm{ac}} \times \ln ($ Alkalinity $\times \mathrm{pH})$
$\mathrm{pH}_{\mathrm{HPAC}}=A_{\mathrm{ad}}+B_{\mathrm{ad}} \times \ln \left(\frac{\text { Alkalinity } \times \mathrm{pH}}{\mathrm{DOC}}\right)$

where, $A_{\mathrm{aa}}, B_{\mathrm{aa}}, A_{\mathrm{ab}}, B_{\mathrm{ab}}, A_{\mathrm{ac}}, B_{\mathrm{ac}}, A_{\mathrm{ad}}$ and $B_{\mathrm{ad}}$ are constants. High co-efficient of determination values $\left(R^{2}\right.$ $=0.832,0.771,0.857$ and 0.822 ) were obtained for the four mathematical models fitted Eqs. (2), (3), (4) and (5), respectively, showing that these explained most of the data.
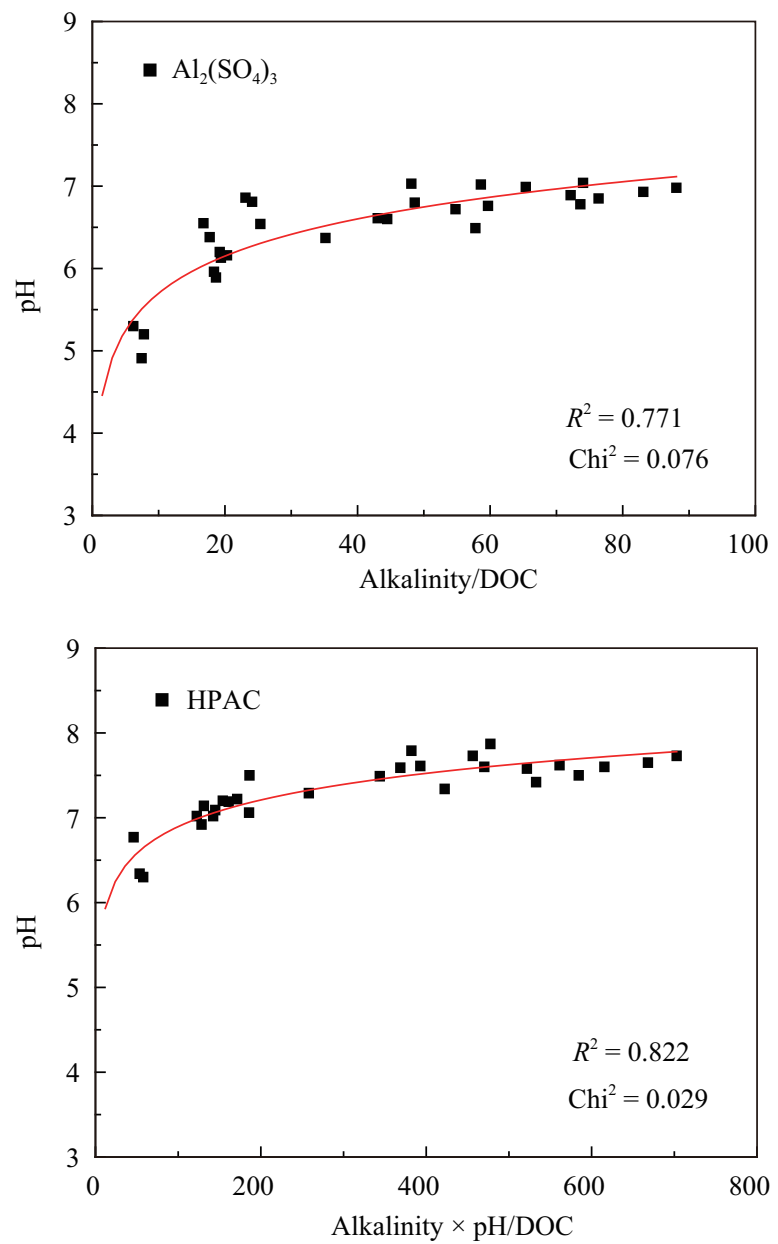

Fig. 2 Relationships between the final $\mathrm{pH}$ after enhanced coagulation for the four coagulants and the independent variables in models (2), (3), (4) and (5). 


\subsection{Optimization of models based on DOM fractiona- tion characteristics}

DOM is a complex matrix predominantly of a wide range of naturally occurring organic compounds. Generally, hydrophobic and higher molecular weight fractions of DOM are more favourably removed by coagulation than other fractions, i.e., hydrophilic and lower molecular weight DOM (Chow et al., 2008; van Leeuwen et al., 2005). Representing the total DOM, the parameter DOC could not reveal the difference in coagulation characteristics between the different chemical fractions or physical fractions in DOM (Chow et al., 2005). Therefore the relationships between the $\mathrm{EC} \mathrm{pH}$ and every chemical and physical fraction of raw water DOM were investigated. It was supposed that, the relationships between the $\mathrm{EC} \mathrm{pH}$ for $\mathrm{FeCl}_{3}, \mathrm{Al}_{2}\left(\mathrm{SO}_{4}\right)_{3}$ and HPAC and the raw water characteristics as described in models (2), (3) and (5) could be optimized. This could be done by identifying the most correlative DOM fractions and replacing the parameter "DOC" in above models by the contents of these DOM fractions.

\subsubsection{Chemical fractions of DOM}

In the previous work, the DOMs in the 29 raw water samples have been characterized using chemical fractionation (Xie, 2011). The parameter "DOC" in independent variables of models (2), (3) and (5) was replaced by the content of every chemical fraction of raw water DOM, i.e. HoB, HoN, HoA, WHoA, HiM, SHoM and HoM. The relationships between the $\mathrm{EC} \mathrm{pH}$ for $\mathrm{FeCl}_{3}, \mathrm{Al}_{2}\left(\mathrm{SO}_{4}\right)_{3}$ and HPAC and the new independent variables were analyzed statistically.

It was found that the ratio of alkalinity to SHoM content $\left(R^{2}=0.918\right)$, the ratio of alkalinity to SHoM content $\left(R^{2}\right.$ $=0.849$ ) and the ratio of the product of alkalinity and $\mathrm{pH}$ to SHoM content $\left(R^{2}=0.842\right)$ of raw water showed highest $R^{2}$ values with the $\mathrm{EC} \mathrm{pH}$ for $\mathrm{FeCl}_{3}, \mathrm{Al}_{2}\left(\mathrm{SO}_{4}\right)_{3}$ and HPAC, respectively. Therefore, the "SHoM content (DOC $\times \mathrm{SHoM} \%)$ " was selected to replace the "DOC" in models (2), (3) and (5). Three new models with the SHoM variables were obtained as follows:

$\mathrm{pH}_{\mathrm{FeCl}_{3}}=A_{\mathrm{ba}}+B_{\mathrm{ba}} \times \ln \left(\frac{\text { Alkalinity }}{\mathrm{DOC} \times \mathrm{SHoM} \%}\right)$

$\mathrm{pH}_{\mathrm{Al}_{2}\left(\mathrm{SO}_{4}\right)_{3}}=A_{\mathrm{bb}}+B_{\mathrm{bb}} \times \ln \left(\frac{\text { Alkalinity }}{\mathrm{DOC} \times \mathrm{SHoM} \%}\right)$

$\mathrm{pH}_{\mathrm{HPAC}}=A_{\mathrm{bd}}+B_{\mathrm{bd}} \times \ln \left(\frac{\text { Alkalinity } \times \mathrm{pH}}{\text { DOC } \times \text { SHoM\% }}\right)$

where, $A_{\mathrm{ba}}, B_{\mathrm{ba}}, A_{\mathrm{bb}}, B_{\mathrm{bb}}, A_{\mathrm{bd}}$ and $B_{\mathrm{bd}}$ are constants.

Compared to the $R^{2}$ values of the model relationships between the EC pH and DOC of raw water in models (2), (3) and (5), the $R^{2}$ values between the EC $\mathrm{pH}$ and the hydrophobic DOM content of raw water in models (6), (7) and (8) were higher. It indicated that the $\mathrm{EC} \mathrm{pH}$ for $\mathrm{FeCl}_{3}, \mathrm{Al}_{2}\left(\mathrm{SO}_{4}\right)_{3}$ and HPAC was actually influenced by the content of hydrophobic DOM in raw water.

\subsubsection{Physical fractions of DOM}

In the previous work, the DOMs in the 29 raw water samples were also characterized using physical fractionation (Xie, 2011). The parameter "DOC" in independent variables of models (2), (3) and (5) was replaced by the content of every physical fraction of raw water DOM, including Peak 1, Peak 2, Peak 3, Peak 4, Peak 5, Peak 4,5 and Peak 3,4,5. The relationships between the EC $\mathrm{pH}$ for $\mathrm{FeCl}_{3}, \mathrm{Al}_{2}\left(\mathrm{SO}_{4}\right)_{3}$ and HPAC and the new independent variables was analyzed.

It was found that the ratio of alkalinity to Peak 4,5 content $\left(R^{2}=0.930\right)$, the ratio of alkalinity to Peak 4,5 content $\left(R^{2}=0.889\right)$ and the ratio of the product of alkalinity and $\mathrm{pH}$ to Peak 4,5 content $\left(R^{2}=0.867\right)$ of raw water showed highest $R^{2}$ values with the $\mathrm{EC} \mathrm{pH}$ for $\mathrm{FeCl}_{3}$, $\mathrm{Al}_{2}\left(\mathrm{SO}_{4}\right)_{3}$ and HPAC, respectively. The Peak 4,5 content (DOC $\times$ Peak 4,5\%) was subsequently selected to replace the "DOC" in models (2), (3) and (5). The further three new models were derived as follows:

$\mathrm{pH}_{\mathrm{FeCl}_{3}}=A_{\mathrm{ca}}+B_{\mathrm{ca}} \times \ln \left(\frac{\text { Alkalinity }}{\text { DOC } \times \text { Peak4, } 5 \%}\right)$

$\mathrm{pH}_{\mathrm{Al}_{2}\left(\mathrm{SO}_{4}\right)_{3}}=A_{\mathrm{cb}}+B_{\mathrm{cb}} \times \ln \left(\frac{\text { Alkalinity }}{\text { DOC } \times \text { Peak } 4,5 \%}\right)$

$\mathrm{pH}_{\mathrm{HPAC}}=A_{\mathrm{cd}}+B_{\mathrm{cd}} \times \ln \left(\frac{\text { Alkalinity } \times \mathrm{pH}}{\text { DOC } \times \text { Peak } 4,5 \%}\right)$

where, $A_{\mathrm{ca}}, B_{\mathrm{ca}}, A_{\mathrm{cb}}, B_{\mathrm{cb}}, A_{\mathrm{cd}}$ and $B_{\mathrm{cd}}$ are constants.

Compared with the $R^{2}$ values of models (2), (3) and (5) between the EC $\mathrm{pH}$ and DOC of raw water, the $R^{2}$ values of models (9), (10) and (11) between the EC pH and the higher AMW DOM content of raw water was also higher. It indicated that the $\mathrm{EC} \mathrm{pH}$ was also impacted by the content of higher AMW DOM in raw water.

\subsubsection{Removable DOM}

From the above results, it is evident that the $\mathrm{EC} \mathrm{pH}$ is influenced by the content of hydrophobic DOM or higher AMW DOM in raw water, which actually were both the removable DOM by enhanced coagulation. It was supposed that, the models (2), (3) and (5) could be further optimized by replacing the parameter "DOC" by the content of all removable DOM by enhanced coagulation.

Before the replacement, the content of removable DOM by enhanced coagulation of $\mathrm{FeCl}_{3}, \mathrm{Al}_{2}\left(\mathrm{SO}_{4}\right)_{3}$ and HPAC should be determined. Generally, the hydrophobic and higher AMW DOM fractions are recognized as being more readily removable by enhanced coagulation (Chow et al., 2008; van Leeuwen et al., 2005). In the previous work, the relationships between the DOM removal efficiency by enhanced coagulation using the three coagulants and the percentages of hydrophobic fractions $(\mathrm{HoB}, \mathrm{HoN}, \mathrm{HoA}$, SHoM and HoM) and higher AMW DOM fractions (Peak 3, Peak 4, Peak 5, Peak 4,5 and Peak 3,4,5) have been analyzed using the data of 29 raw water samples (Xie, 2011). A high degree of linear correlation was found between them. The percentage of SHoM (SHoM\%, $R^{2}$ : 0.849-0.908) and the percentage of Peak 4,5 (Peak 4,5\%, 
$R^{2}: 0.798-0.873$ ) showed highest $R^{2}$ values with the DOM removal efficiency by enhanced coagulation for the three coagulants. Based on the above, the models of DOM removal efficiency by enhanced coagulation for the three coagulants could be readily established. The following linear function was adopted as the basic model to represent the mathematical relationship:

$y=A^{\prime}+B^{\prime} \times x$

where, $y$ is the dependent variable, $x$ is the independent variable, and $A^{\prime}$ and $B^{\prime}$ are constants.

The SHoM\% and the Peak $4,5 \%$ were selected as the independent variables respectively based on the chemical fractionation and the physical fractionation. The models of DOM removal efficiency by enhanced coagulation for the three coagulants $\left(R_{\text {coagulant }}\right)$ were determined as follows:

$R_{\mathrm{FeCl}_{3}}=A_{\mathrm{a} 1}+B_{\mathrm{a} 1} \times \mathrm{SHoM} \%$

$R_{\mathrm{FeCl}_{3}}=A_{\mathrm{a} 2}+B_{\mathrm{a} 2} \times$ Peak $4,5 \%$

$R_{\mathrm{Al}_{2}\left(\mathrm{SO}_{4}\right)_{3}}=A_{\mathrm{b} 1}+B_{\mathrm{b} 1} \times \mathrm{SHoM} \%$

$R_{\mathrm{Al}_{2}\left(\mathrm{SO}_{4}\right)_{3}}=A_{\mathrm{b} 2}+B_{\mathrm{b} 2} \times$ Peak $4,5 \%$

$R_{\mathrm{HPAC}}=A_{\mathrm{d} 1}+B_{\mathrm{d} 1} \times \mathrm{SHoM} \%$

$R_{\mathrm{HPAC}}=A_{\mathrm{d} 2}+B_{\mathrm{d} 2} \times$ Peak $4,5 \%$

where, $A_{\mathrm{a} 1}, A_{\mathrm{a} 2}, B_{\mathrm{a} 1}, B_{\mathrm{a} 2}, A_{\mathrm{b} 1}, A_{\mathrm{b} 2}, B_{\mathrm{b} 1}, B_{\mathrm{b} 2}, A_{\mathrm{d} 1}, A_{\mathrm{d} 2}, B_{\mathrm{d} 1}$ and $B_{\mathrm{d} 2}$ are all constants.

The contents of the removable DOM by enhanced coagulation for the three coagulants could be quantified by above models (14), (16) and (18) based on physical fractionation. The removable DOM contents, i.e. "DOC Rcoagulant", of the three coagulants were selected to replace the "DOC" in models (2), (3) and (5). Another three new models of EC $\mathrm{pH}$ were obtained as follows:

$\mathrm{pH}_{\mathrm{FeCl}_{3}}=A_{\mathrm{da}}+B_{\mathrm{da}} \times \ln \left(\frac{\text { Alkalinity }}{\mathrm{DOC} \times\left(A_{\mathrm{a} 2}+B_{\mathrm{a} 2} \times \text { Peak4, 5\% }\right)}\right)$

$\mathrm{pH}_{\mathrm{Al}_{2}\left(\mathrm{SO}_{4}\right)_{3}}=A_{\mathrm{db}}+B_{\mathrm{db}} \times \ln \left(\frac{\text { Alkalinity }}{\mathrm{DOC} \times\left(A_{\mathrm{b} 2}+B_{\mathrm{b} 2} \times \text { Peak4, 5\% }\right)}\right)$

$\mathrm{pH}_{\mathrm{HPAC}}=A_{\mathrm{dd}}+B_{\mathrm{dd}} \times \ln \left(\frac{\text { Alkalinity } \times \mathrm{pH}}{\mathrm{DOC} \times\left(A_{\mathrm{d} 2}+B_{\mathrm{d} 2} \times \text { Peak4, 5\%) }\right.}\right)$

where, $A_{\mathrm{da}}, B_{\mathrm{da}}, A_{\mathrm{db}}, B_{\mathrm{db}}, A_{\mathrm{dd}}$ and $B_{\mathrm{dd}}$ are constants.

High $R^{2}$ values $(0.936,0.905$ and 0.869$)$ were obtained for the three coagulants $\mathrm{FeCl}_{3}, \mathrm{Al}_{2}\left(\mathrm{SO}_{4}\right)_{3}$ and HPAC, respectively (Fig. 3).
In the same way, the content of the removable DOM by enhanced coagulation for the three coagulants could be quantified by the above models (13), (15) and (17) based on chemical fractionation. Another three models with high $R^{2}$ values using the chemical fraction "SHoM\%" as an input parameter could also be obtained.

The EC $\mathrm{pH}$ showed improved model fitting (higher $R^{2}$ values) with all removable DOM content of raw water in models (19), (20) and (21) than the hydrophobic fraction content of raw water in models (6), (7) and (8) or the higher AMW fraction content of raw water in models (9), (10) and (11). This indicates that the $\mathrm{EC} \mathrm{pH}$ was most influenced by the content of entire removable DOM by enhanced coagulation rather than the individual hydrophobic fractions or high AMW fractions in raw water DOM.

\subsection{Preliminary validation of the prediction accuracy of the models}

The Changsha Xiangjiang River (CX) source water beyond the thirteen investigated source waters was employed to preliminarily validate the above models of $\mathrm{EC} \mathrm{pH}$ for prediction purpose. The CX raw water was characterized by the general water quality parameters and the chemical and physical fractionation, and the jar tests of enhanced coagulation using the four coagulants without $\mathrm{pH}$ control were conducted. The models (19), (20), (4), and (21) were selected to predict the $\mathrm{EC} \mathrm{pH}$ for $\mathrm{FeCl}_{3}, \mathrm{Al}_{2}\left(\mathrm{SO}_{4}\right)_{3}$, $\mathrm{PACl}$ and HPAC, respectively. The predicted data were compared with the actual data determined by the jar tests and are shown in Table 1. The low deviation was found, indicating that the predicted data matched well with the actual data.

The results of preliminary validation of the developed models indicate the potential for their application in practical operation of drinking water treatment plant to predict the final $\mathrm{pH}$ after enhanced coagulation without $\mathrm{pH}$ control for maximum DOM removal. However, further validation

Table 1 Comparison of the model predicted data with the actual data for the Changsha Xiangjiang River source water

\begin{tabular}{lrr}
\hline & \multicolumn{2}{c}{ Final $\mathrm{pH}$ after enhanced coagulation } \\
\cline { 2 - 3 } & Actual & Predicted \\
\hline $\mathrm{FeCl}_{3}$ & 6.86 & 6.81 \\
$\mathrm{Al}_{2}\left(\mathrm{SO}_{4}\right)_{3}$ & 7.02 & 7.00 \\
$\mathrm{PACl}$ & 7.70 & 7.64 \\
$\mathrm{HPAC}$ & 7.62 & 7.67 \\
\hline
\end{tabular}
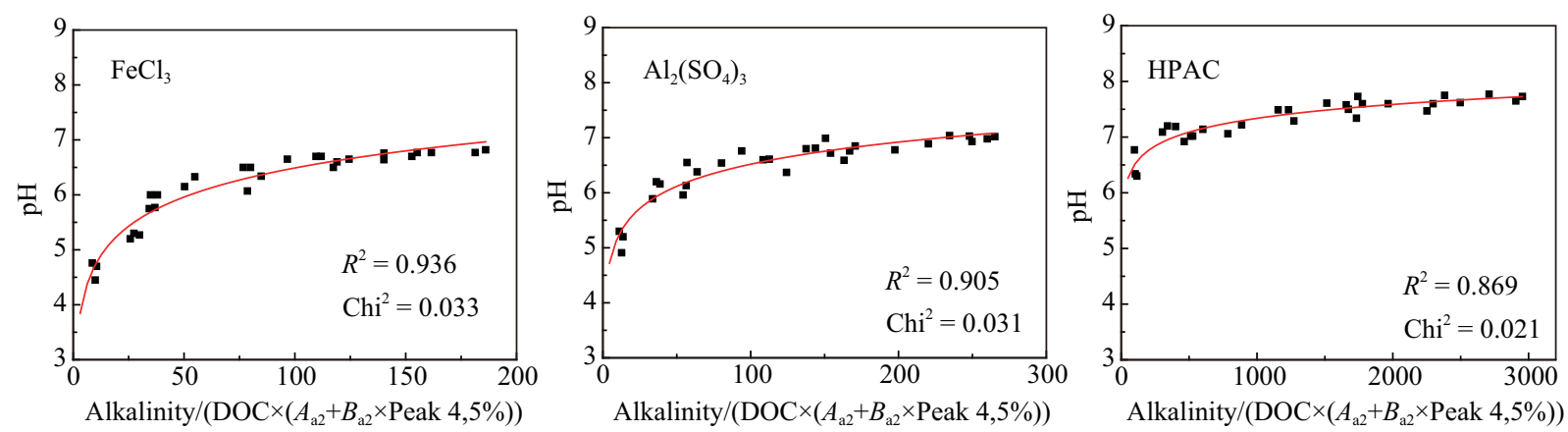

Fig. 3 Relationships between the final EC pH for three coagulants and the independent variables in models (19), (20), and (21). 
is still needed before practical application can be done, including the validation by jar tests of more Chinese or worldwide source waters beyond those investigated waters in this article and the validation by pilot plant trials.

The application of the developed models could be based on the practical analytical ability and instrument condition at the drinking water treatment plant. More advanced characterization technique is employed, more precise the prediction capability will be. However in practice, the prediction should be balanced by the need for precision and the costs and time required by the advanced DOM characterization techniques. Moreover in practice, the application of the models should be following thorough validation and calibration for specific waters and water treatment operations. This feed-forward prediction modeling approach might be improved or made more robust through model development to include feed-back parameters from the treated water quality to provide reliable and accurate data of final $\mathrm{pH}$ after enhanced coagulation.

\section{Conclusions}

A set of feed-forward semi-empirical models with $R^{2}$ values was developed and optimized from which the final $\mathrm{pH}$ after enhanced coagulation can be predicted. Optimized models have input data of removable DOM based on hydrophobicity and AMW. Models were developed for four coagulants, $\mathrm{FeCl}_{3}, \mathrm{Al}_{2}\left(\mathrm{SO}_{4}\right)_{3}, \mathrm{PACl}$ and HPAC and applied to the enhanced coagulation for maximum DOM removal without $\mathrm{pH}$ control. These models were preliminarily validated using one kind of water collected from Changsha Xiangjiang River, and prediction results showed low deviation from the actual data. This finding indicates the possibility for the application of these models in practical operation at drinking water treatment plants. However further validation is still required. In practice, the prediction of final $\mathrm{pH}$ after enhanced coagulation using the models should take into account the costs and time of advanced DOM characterization techniques, the site specific testing requirements and the potential of further model development for improved prediction capacity.

\section{Acknowledgments}

This work was supported by the National Natural Science Foundation of China (No. 50921064, 51025830), the National Basic Research Program (973) of China (No. 2011CB933700), and the Special Co-construction Project of Beijing Municipal Commission of Education. The authors are grateful for the kind support from the local water companies and colleagues.

\section{References}

Allpike B P, Heitz A, Joll C A, Kagi R I, Abbt-Braun G, Frimmel F H et al., 2005. Size exclusion chromatography to characterize DOC removal in drinking water treatment. Environmental Science and Technology, 39(7): 2334-2342.
Baxter C W, Stanely S J, Zhang Q, 1999. Development of a full-scale artificial neural network model for the removal of natural organic matter by enhanced coagulation. Aqua, 48(4): 129-136.

Bolto B, Dixon D, Eldridge R, King S, 2001. Cationic polymer and clay or metal oxide combinations for natural organic matter removal. Water Research, 35(11): 2669-2676.

Chin Y P, Aiken G, O'Loughlin E, 1994. Molecular weight, polydispersity, and spectroscopic properties of aquatic humic substances. Environmental Science and Technology, 28(11): 1853-1858.

Chow C W K, Fabris R, Drikas M, Holmes M, 2005. A case study of treatment performance and organic character. Journal of Water Supply Research and Technology-Aqua, 54(6): 385395.

Chow C W K, Fabris R, van Leeuwen J, Wang D S, Drikas M, 2008. Assessing natural organic matter treatability using high performance size exclusion chromatography. Environmental Science and Technology, 42(17): 6683-6689.

Chow C W K, van Leeuwen J A, Drikas M, Fabris R, Spark K M, Page D W, 1999. The impact of the character of natural organic matter in conventional treatment with alum. Water Science and Technology, 40(9): 97-104.

Edwards M, 1997. Predicting DOC removal during enhanced coagulation. Journal American Water Works Association, 89(5): 78-89.

Gjessing E T, Alberts J J, Bruchet A, Egeberg P K, Lydersen E, McGown L B et al., 1998. Multi-method characterisation of natural organic matter isolated from water: Characterisation of reverse osmosisisolates from water of two semi-identical dystrophic lakes basins in Norway. Water Research, 32(10): 3108-3124.

Her N, Amy G, Sohn J, von Gunten U, 2008. UV absorbance ratio index with size exclusion chromatography (URI-SEC) as an NOM property indicator. Journal of Water Supply Research and Technology-Aqua, 57(1): 35-44.

Kastl G, Sathasivan A, Fisher I, Van Leeuwen J, 2004. Modeling DOC removal by enhanced coagulation. Journal American Water Works Association, 96(2): 79-89.

Kitis M, Karanfil T, Wigton A, Kilduff J E, 2002. Probing reactivity of dissolved organic matter for disinfection by-product formation using XAD-8 resin adsorption and ultrafiltration fractionation. Water Research, 36(15): 3834-3848.

Leenheer J A, 1981. Comprehensive approach to preparative isolation and fractionation of dissolved organic carbon from natural waters and wastewaters. Environmental Science and Technology, 15(5): 578-587.

Leenheer J A, Croue J P, 2003. Characterizing aquatic dissolved organic matter. Environmental Science and Technology, 37(1): 18A-26A.

MartinMousset B, Croue J P, Lefebvre E, Legube B, 1997. Distribution and characterization of dissolved organic matter of surface waters. Water Research, 31(3): 541-553.

Stanley S, Baxter C, Zhang Q, Shariff R, 2000. Process Modeling and Control of Enhanced Coagulation. AWWA Research Foundation and American Water Works Association.

Urfer D, Huck P M, Gagnon G A, Mutti D, Smith F, 1999. Modeling enhanced coagulation to improve ozone disinfection. Journal American Water Works Association, 91(3): 59-73.

van Leeuwen J, Chow C, Fabris R, Withers N, Page D, Drikas $\mathrm{M}, 2002$. Application of a fractionation technique for better understanding of the removal of natural organic matter by alum coagulation. In: 3rd World Water Congress: Drinking Water Treatment, Melbourne, Australie. 7-12, April. 2(5- 
6): 427-433.

van Leeuwen J, Daly R, Holmes A, 2005. Modeling the treatment of drinking water to maximize dissolved organic matter removal and minimize disinfection by-product formation. Desalination, 176(1-3): 81-89.

van Leeuwen J, Holmes M, Heidenreich C, Daly R, Fisher I, Kastl $\mathrm{G}$ et al., 2003. Modelling the application of inorganic coagulants and $\mathrm{pH}$ control reagents for removal of organic matter from drinking waters. Proc. Modsim 2003, Townsville, Australia. 1835-1840.

Vuorio E, Vahala R, Rintala J, Laukkanen R, 1998. The evaluation of drinking water treatment performed with HPSEC. Environment International, 24(5-6): 617-623.
Wei Q S, Wang D S, Wei Q, Qiao C G, Shi B Y, Tang H X, 2008. Size and resin fractionations of dissolved organic matter and trihalomethane precursors from four typical source waters in China. Environmental Monitoring and Assessment, 141(1-3): 347-357.

Xie J K, 2011. Dissolved organic matter and its enhanced coagulation in Chinese typical source waters: Survey, characterization and modeling. Ph.D Thesis. Chinese Academy of Sciences, Beijing, China.

Yan M Q, Wang D S, Yu J F, Ni J R, Edwards M, Qu J H, 2008. Enhanced coagulation with polyaluminum chlorides: Role of pH/Alkalinity and speciation. Chemosphere, 71(9): 1665-1673.

\title{
Call for Grant Proposals
}

\section{Estée Lauder Companies

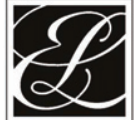 \\ ESTĒE LAUDER}

Research grants up to RMB 630,000 per applicant will be awarded to sponsor research that furthers our understanding of the effects of pollution on human skin health and skin aging. A total of RMB 1,260,000 will be disbursed.

\begin{abstract}
About Estée Lauder Companies
Headquartered in New York, with Asian Research facilities in Tokyo, Kobe and Shanghai, the Estée Lauder group of companies is one of the world's leading manufacturers and marketers of quality skin care, makeup, fragrance and hair care products. As a truly global company, we aim to understand the needs of consumers worldwide as we continue to create the best quality, high-performance products while maintaining a strong commitment to social and environmental responsibility.
\end{abstract}

\section{The Key Aims of This Program}

For decades, extrinsic skin aging has been known to result from chronic exposure to solar radiation. Cigarette smoke has also been shown to damage skin, and most recently, industrial and traffic related ambient particulate matter has been correlated with facial wrinkles and pigmentary changes.

Extrinsic aging is amenable to prevention and amelioration. The Estée Lauder family of companies desire to more thoroughly understand, for global application, the impact of environmental pollution on skin in individuals of Chinese ancestry. Acceptable project proposals may address the effects of pollution on visible signs of skin aging through epidemiological studies, prospective clinical studies or in vitro mechanistic research. The spectrum of biology, physiology, environmental science that can be addressed through this grant is necessarily broad and could, for example, include sources of pollution such as ozone, metals, traffic-related particulates and polycyclic aromatic hydrocarbons, other products of fossil fuel combustion, cigarette smoking and indoor air pollution. Grants are intended to fund one-year projects.

\section{Eligibility Requirements}

Research must be under the sponsorship of a PRC university or research institute and the principal investigator must be appointed to an academic department of the university or a research division of the research institute.

\section{Deadlines:}

- Application packets must be submitted by email no later than March 15, 2012.

- Awards will be determined no later than May 1, 2012.

- Funding will be available June 30, 2012 subject to acceptance of additional terms and conditions

\section{Interested parties please email for further information:}

Qiong Wang

Estée Lauder China Grant Project Group

Building 8, NO 88, Da Er Wen Rd, Shanghai 201203

E-mail: qiwang@cn.estee.com

Tel: (86) 21 5132-8960*116 